\title{
A Case Report of Endoscopic Transoral Laser Excision of a Rare Hamartoma Arising in the Oropharynx
}

\author{
Mir Saifullah*1, Mir Fasihullah ${ }^{2}$ and Mir Aisha ${ }^{2}$ \\ ${ }^{1}$ Department of consultant ENT, Head and Neck surgeon, Pakistan \\ ${ }^{2}$ Department of ENT, Pakistan
}

*Corresponding author: Mir Saifullah, Department of consultant ENT, head and neck surgeon, Pakistan

\begin{tabular}{|c|c|}
\hline ARTICLE INFO & ABSTRACT \\
\hline Received: April 15, 2019 & Transoral laser microsurgery is increasingly being used to access difficult to access \\
\hline Published: April 25, 2019 & $\begin{array}{l}\text { areas. When aided with endoscopes which angular vision leads to significant decrease in } \\
\text { morbidity. A diode laser was used in this surgery which had the added advantage of being }\end{array}$ \\
\hline $\begin{array}{l}\text { Citation: Mir Saifullah, Mir Fasihul- } \\
\text { lah, Mir Aisha. Upper Extremity Pain }\end{array}$ & $\begin{array}{l}\text { fiber delivered to provide excellent haemostasis. Hamartomas are extremely rare benign } \\
\text { lesion that occur anywhere in the body but are very rare in the pharynx. We discuss a case } \\
\text { of } 10 \text { year old girl who underwent excision of tumor using this technique. }\end{array}$ \\
\hline
\end{tabular}
in Spinal Cord Injury (Sci) Patients. Biomed J Sci \& Tech Res 17(3)-2019. BJSTR. MS.ID.003003.

\section{Introduction}

Transoral laser microsurgery (TLM) is a minimally invasive surgical approach to functional organ preservation for tumors of the upper aero digestive tract. It involves tumor resection using specialized endoscopic instruments, microscopes and lasers, with the wound bed often left to heal by secondary intention [1]. The term TLM was first coined by John Salassa of Mayo Clinic in the 1990s [2]. Hamartomas are rare benign neoplasms with only five cases reported in the head and neck [3]. They arise due to clonal chromosomal aberrations. They exhibit a disordered growth pattern and grow at the same rate as the surrounding tissue in any parts of the body. Only 3 reported cases have been reported in the oropharynx [4,5] \& (Figure 1). The use of Rigid Hopkins endoscopes in surgery allows for high definition angled magnified view. It is used for access without causing morbidity. Diode laser in surgery allows for precision cutting \& excellent hemostatic control. It significantly reduces surgical time and better functional results [6].

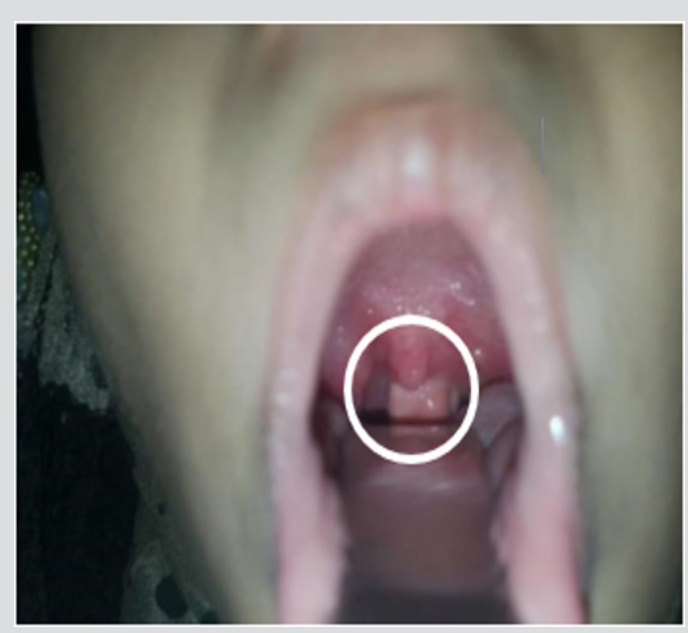

Figure 1: Shows a white polypoidal mass in the oropharynx just behind the uvula. 


\section{Case Presentation}

A 10-year-old female child presented to out Patient Department at Dr. Fasih's Ent \& General Hospital Karachi, Pakistan. She gave a history of progressive nasal obstruction for 5 years, ear blockage for 3 years, change of voice for 1year. According to the patient she was in her usual state of health before when developed bilateral slowly progressive nasal obstruction not exacerbated by pollen, dust or change of seasons. It was relieved by medications. She reported as having ear blockage intermittently with each lasting approximately 3 weeks relieved medication given by her local GP. Her mother noticed a change in voice with denasal character along with snoring, mouth breathing, and chronic cough. It was not associated nasal regurgitation of food. At this point she sought expert opinion. The patient had no known drug allergies or significant past medical, surgical. Her socio-economic status is fair. There no reports fever, weight loss. On examination she was a pleasant, playful 10 year old sitting comfortably in an examination chair.
Her vital and sub vitals were within normal limits. On examination of the nose, on inspection her polypoidal soft tissue mass in her oropharynx (Figure 2). She underwent computerized tomogram (CT) which showed a lobulated mass in the midline of the oropharynx. Anteriorly it is attaching to the soft palate measuring 2 $\mathrm{x} 1 \mathrm{~cm}$. It is showing no communication with the paranasal sinuses (Figure 3). to suggest it to be an antro choanal polyp. Subsequently an excisional Biopsy was under taken with help of 70 degree Rigid Hopkins endoscopes and a diode laser (Figure 4) and the specimen was sent for histopathology. The patient had an uneventful recovery and was discharged after an overnight stay. The Histopathology showed light brown firm irregular nodular mass measuring 2.3 $\mathrm{x} 1.7 \mathrm{~cm} \times 1.3 \mathrm{~cm}$ with cut areas showing no7dular areas with calcification. On microscopy, shows polypoid fibro fatty tissue covered b stratified squamous epithelium with some cartilage. It was concluded to be hamartomous polyp of the oropharynx (Figure $5)$.

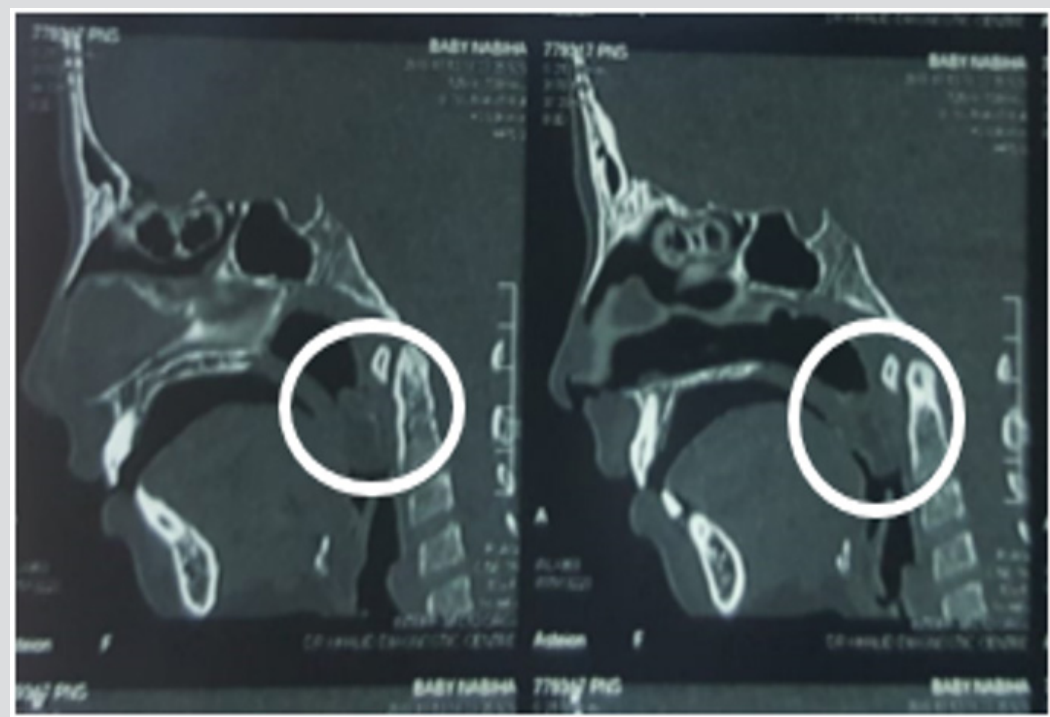

Figure 2: CT neck sagittal cut shows a soft tissue mass arising from the soft palate and a butting the posterior pharyngeal wall.

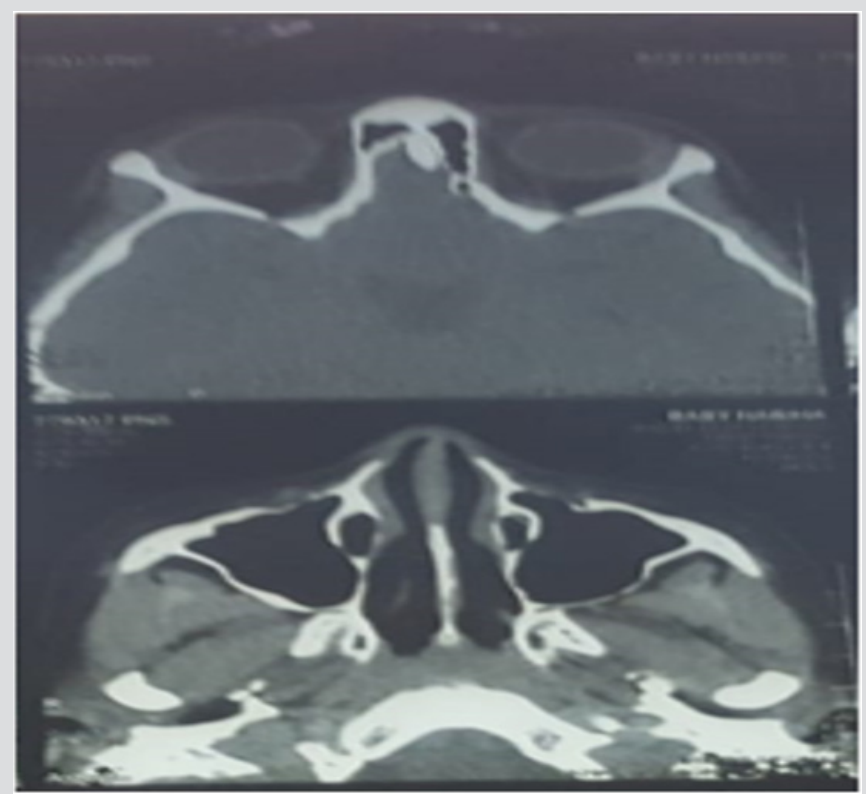

Figure 3: CT scan neck axial cut shows normal para nasal sinuses orbit with no intra cranial extension. 


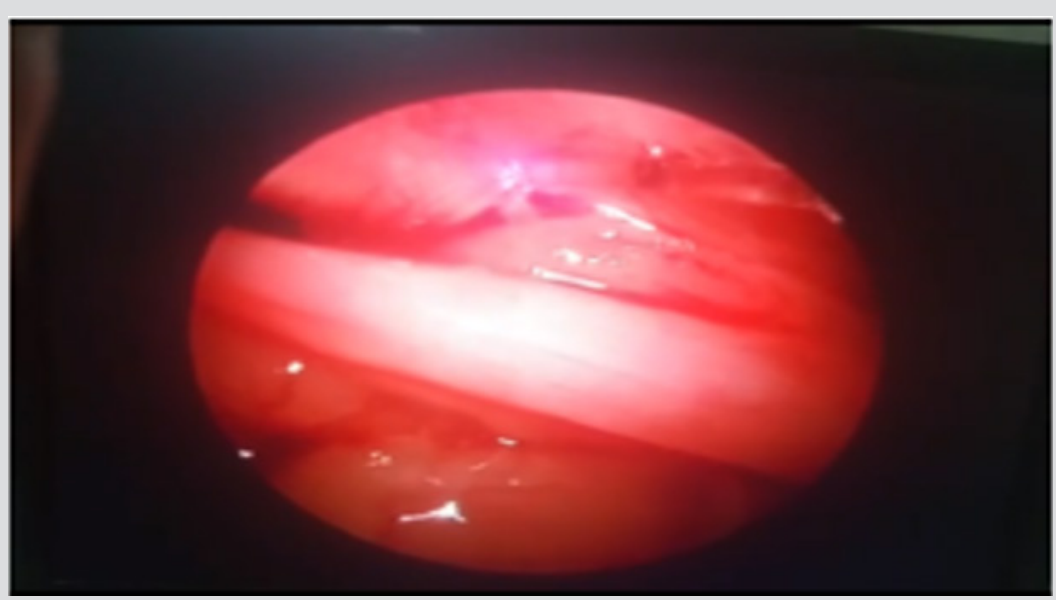

Figure 4: Shows a 70 degree rigid endoscopic view of diode laser excision.

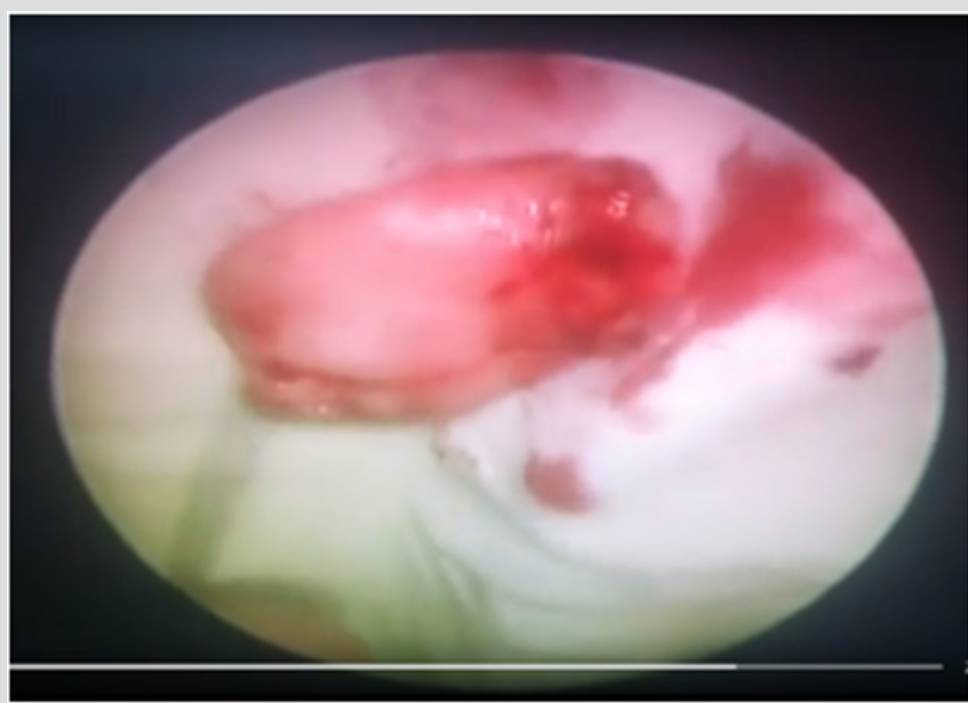

Figure 5: Shows a tumor of hamartoma after excision.

\section{Discussion}

The 70 degree Rigid Hopkins Endoscopes provide excellent visualization because of the angled magnified view. It has changed the otolaryngoloical surgery of the pharynx and larynx where traditional approaches such as lateral pharyngtomy and transpalatal approaches caused significant morbidity. Diode Laser has a wave length of $532 \mathrm{~nm}$ at which they deliver energy to tissue allowing for their evaporation along with simultaneous hemostasis. It also has the advantage of being fiber delivered making it superior to other lasers which work in non-contact mode at can damage other vital structures.

\section{Conclusion}

An understanding of the equipment required to achieve optimal surgical access and the pertinent factors influencing patient selection are key for the practice of TLM. Surgeons of the future need to familiarize themselves with the operating room set-up and operative technique of TLM throughout their training to offer this approach as part of a modern and integrated multidisciplinary head and neck cancer service.

\section{References}

1. Grant DG, Salassa JR, Hinni ML, Pearson BW, Perry WC, et al. (2006) Carcinoma of the tongue base treated by transoral laser microsurgery, part 1: Untreated tumors, a prospective analysis of oncologic and functional outcomes. Laryngoscope 116(12): 2150-2155.

2. Steiner W (1993) Results of curative laser micro-surgery of laryngeal carcinomas. Am J Otolaryngology 14(2): 116-121.

3. RK Jain (1999) Hamartoma of the head and neck. Indian J Otolaryngol Head Neck Surg 51(4): 76-78.

4. DPG Albrecht (1904) Hamartia.

5. (2008) Hamartoma, Taber's Medical Dictionary, Retrieved p. 9-2.

6. Reinisch L (1996) Laser physics and tissue inter-actions. Otolaryngol Clin North Am 29(6): 893-914. 


\section{ISSN: 2574-1241}

DOI: 10.26717/BJSTR.2019.17.003003

Mir Saifullah. Biomed J Sci \& Tech Res

(c) (i) This work is licensed under Creative

Submission Link: https://biomedres.us/submit-manuscript.php

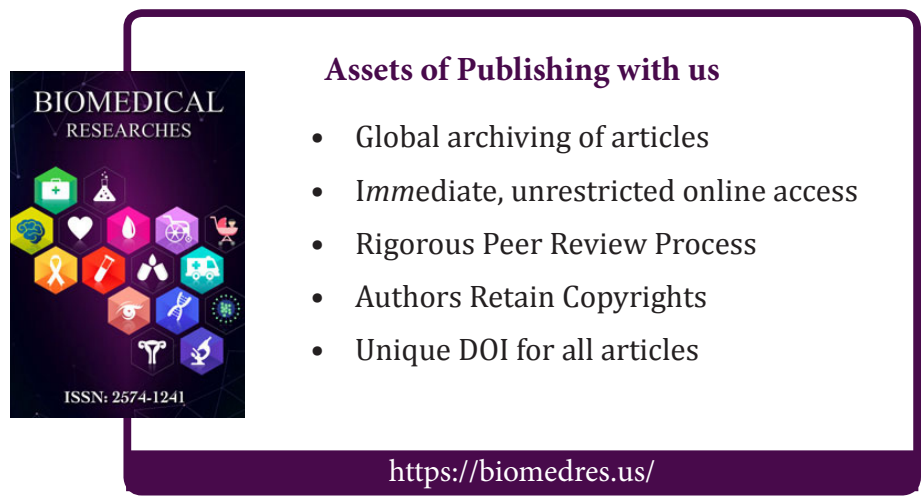

